\title{
Novas perspectivas no processamento e divulgação de informações públicas
}

\author{
New perspectives on the processing and \\ release of public information
}

Elizabeth Sardelli MAZINIי

Marilda Lopes Ginez de LARA ${ }^{2}$

\section{RE S U M O}

Presente estudo aborda questões relacionadas à organização e à recepção da informação no contexto dos serviços e dos sistemas de informação pública impulsionados pela tecnologia. Parte-se do pressuposto de que na sociedade "tecnologizada," a distância entre usuários e informação é, quase sempre, uma distância cognitiva e sociocultural, fruto da nossa dificuldade em desenhar a comunicação. Nesse contexto, privilegiamos a abordagem da informação como signo, procurando responder como uma mensagem documentária transforma-se em informação, isto é, uma estrutura reconhecida como útil socialmente. Observando os aspectos estruturais, cognitivos e comunicativos da mensagem documentária, com base na Linguística Documentária, na Terminologia e na Linguística Textual, é analisada a política de gestão do conhecimento e inovação do Governo do Estado de São Paulo, que autoriza o uso da web 2.0, questionando-se em que medida a iniciativa representa inovações no ambiente das bibliotecas.

Palavras-chave: Biblioteca. Disseminação da informação. Informação pública. Recuperação da informação.

\section{A B S T R A C T}

This article discusses issues related to the organization and reception of information in the context of services and public information systems driven by technology. It stems from the assumption that in a "technologized" society, the distance between users and information is almost always of cognitive and socio-cultural nature, a product of our effort to design communication. In this context, we favor the approach of the information sign, seeking to answer how a documentary message turns into information, i.e. a structure recognized as socially useful. Observing the structural, cognitive and communicative aspects of the documentary message, based on Documentary Linguistics, Terminology, as well as on Textual Linguistics, the policy of knowledge management and innovation of the Government of the State of São Paulo is analyzed, which authorizes the use of Web 2.0, also questioning to what extent this initiative represents innovation in the environment of libraries.

Keywords: Library. Dissemination of information. Public information. Information retrieval.

\footnotetext{
1 Professora, Fundação Escola de Sociologia e Política de São Paulo, Faculdade de Biblioteconomia e Ciência da Informação. R. Dr. Cesário Mota Júnior, 262, 01221-020, São Paulo, SP, Brasil. Correspondência para/Correspondence to: E.S. MAZINI. E-mail: <esmazini@terra.com.br>.

2 Professora Doutora, Universidade de São Paulo, Escola de Comunicação e Artes. São Paulo, SP, Brasil.

Recebido em 11/1/2010 e aceito para publicação em 25/11/2010.
} 


\section{NTRODU ÇÃ O}

Na sociedade tecnologizada, há um aumento exponencial da oferta de informação de interesse público, o que não quer dizer que as dificuldades dos usuários para chegarem à informação desejada tenham sido superadas de maneira ótima. No âmbito da ciência da informação, o princípio da relevância, em prejuízo da quantidade, promove a informação a um valor cognitivo expresso por meio de um formato linguístico vinculado às finalidades do uso.

A informação, em primeiro lugar, não pode ser entendida como algo de significado universal que atinge de maneira homogênea todos os seres humanos, e, em segundo lugar, que à categoria usuários correspondem sujeitos coletivos, grupos sociais com perfis e práticas diferenciados. Nesse sentido, a área se afasta da perspectiva da comunicação de massa, cuja premissa é quantitativa, para, na busca de qualificação e eficácia, aproximar-se dos estudos da linguagem com o intuito de produzir informações mais aderentes aos desejos do público usuário.

Privilegiando o foco da recepção, o presente trabalho tem como objetivo identificar o processo de organização, de acesso e de transferência de informações no exame de seus aspectos estruturais, cognitivos e comunicativos. Nessa análise, procuramos considerar a abordagem da informação como signo para responder como uma mensagem documentária transforma-se em informação, isto é, em uma estrutura reconhecida como útil socialmente.

Com o olhar dirigido ao setor público, este estudo enfoca a política de inovações do Governo do Estado de São Paulo - que libera a Internet e incentiva a utilização das ferramentas de web 2.0 para uso da máquina pública - e questiona em que medida tal iniciativa pode interferir no campo da ciência da informação e realizar modificações no ambiente das bibliotecas.

\section{OS DISCURSOS}

TÉCNICO-CIENTÍFICOSE O PAPEL DA CIÊNCIA DA INFORMAÇÃO

Para Santos (1989), todo discurso científico é um discurso anormal, inteligível no âmbito institucional da ciência, mas de difícil assimilação pela opinião pública (discurso normal). Os discursos especializados são vinculados culturalmente, portanto para serem compreendidos socialmente dependem de mudança cultural, um processo protagonizado por cidadãos, comunidade científica amplo senso, governo, equipamentos culturais e mídias em geral (Vogt, 2005). Nos estudos de Vogt (2003; 2005), a espiral da cultura científica representa a dinâmica de produção e de socialização do conhecimento científico. $\bigcirc$ processo tem início com a difusão no âmbito institucional da ciência e vai evoluindo para dois planos intermediários de formação um responsável pelos novos cientistas, iniciado já no ensino fundamental e médio, e outro sensibilizador e informativo, focado na juventude e desempenhado pelos museus e feiras de ciência - para só então atingir a opinião pública. Embora sua perspectiva enfatize o processo de especialização como gradativo, sem reconhecer a possibilidade de outros modos de apropriação que não obedeçam à sequência sugerida, sua proposta põe em relevo modos de circulação da informação usuais em nossos dias.

Em todos os casos acima, a única possibilidade de aproximação entre o universo especializado e o senso comum é pela informação; portanto, sua organização para propiciar a apropriação é fator fundamental de evolução. A informação no sentido de mensagem é definida como discurso reprocessado cuja finalidade é aproximar o conhecimento da realidade dos indivíduos, agregando valores ao estágio cognitivo anterior do mesmo, fomentando sua produção intelectual e a socialização de novos conhecimentos. Para que isso se efetive é preciso que haja entendimento comunicativo, isto é, códigos comuns, vínculos de adesão, formatos e meios adequados.

Na opinião de Capurro (2003), essa ação insere-se no âmbito da comunicação científica porque se refere às construções discursivas transformadas em mensagens ou à produção científica propriamente dita, registrada em documentos e em parte da memória social. A missão da ciência da informação é aproximar esses dois universos por meio de processos que tornem possíveis e compreensíveis a "oferta de sentidos (elaboração de mensagem) e a seleção de sentidos (a recuperação de informação)" (Capurro, 2003, online). Tal proposta tem como base a observação de Luhmann sobre a comunicação como uma unidade que compreende três momentos: oferta de sentido, seleção e compreensão (Capurro, 2003). 
É preciso admitir, contudo, que mesmo dentro de um segmento usuário específico, a identificação da mensagem como informação ocorre em uma situação de comunicação complexa, envolvendo uma rede de fatores de ordem linguística, cognitiva, sociocultural e interacional. Nem sempre a instância de produção consegue prever todos os raciocínios e estratégias possíveis de serem adotadas pelos usuários no momento de busca da informação. Segundo Lara (1999, p. 142):

Cada usuário estabelece, a seu modo, uma formulação baseada na sua experiência colateral e nas suas necessidades particulares, portanto, quanto mais a fonte produtora conseguir explicitar e qualificar as representações oferecidas, mais chance os usuários terão de recuperar informações relevantes e pertinentes aos seus propósitos.

Assim sendo, cabe à ciência da informação procurar formas de responder adequadamente aos complexos problemas de produção/recepção da informação gerados pelo acesso e pela interatividade, aperfeiçoando seus instrumentos de mediação (política de indexação, linguagem documentária, formatos de transferência, indicadores de acompanhamento de necessidades e de uso de informação) com a finalidade de melhorar a oferta à sociedade e a subsequente apropriação.

No âmbito das instituições públicas, trata-se de procurar conhecer as formas de demanda no que diz respeito às temáticas, aos problemas nelas suscitadas, às práticas de recuperação.

\section{AS MUDANÇAS NOMODODE COMPREENDER A INFORMAÇÃO}

O avanço tecnológico mudou o quadro do processamento e da recuperação da informação na medida em que não há mais distâncias que sejam obstáculo à velocidade. Nenhuma fronteira detém a informação, e os sistemas eletrônicos encurtaram o tempo de execução das tarefas de busca e de processamento da informação. Mas, ao mesmo tempo e a despeito dos fatores positivos, a tecnologia provocou, e ainda provoca, forte impacto nas instâncias de produção e de recepção. Inúmeros investimentos sobre a linguagem têm sido empreendidos, considerando o saber científico (e técnico) "uma espécie de discurso" (Lyotard, 2002, p.3). A tecnologia modifica "as operações de aquisição, classificação, acesso e exploração de conhecimentos" (Lyotard, 2002, p.6) e afeta sua circulação.

Nesta transformação geral, a natureza do saber não permanece intacta. Ele não pode se submeter aos novos canais, e tornar-se operacional, a não ser que o conhecimento possa ser traduzido em quantidades de informação. Pode-se então prever que tudo o que no saber constituído não é traduzível será abandonado, e que a orientação das novas pesquisas se subordinará à condição de tradutibilidade dos resultados eventuais em linguagem de máquina (Lyotard, 2002, p.4)

Dentre os impactos, pode-se destacar a substituição da mediação presencial realizada pelas unidades de informação e o documento digital. $O$ desenvolvimento das memórias digitais e das ferramentas tecnológicas colocou em cena a possibilidade de os textos serem condensados e recuperados a partir da linguagem natural em que são escritos. Esse caminho tem confrontado os procedimentos documentários realizados com base nos universos simbólicos particulares. Entretanto, até o momento, não existe solução satisfatória para a recuperação semântica sem a intervenção da inteligência humana. A viabilização dos processos automáticos parte de estudo dos vocabulários e da reelaboração das mensagens a fim de torná-las mais condensadas e diretas. Se, por um lado, a tecnologia apresenta rapidez de geração, facilidade de acesso e possibilidade de circulação de grande massa de informação em tempo recorde, por outro, ocasiona uma sobrecarga de informação ao usuário que se vê sem condições reais para selecioná-las e lê-las. O desafio deste momento histórico de abundância de informação está na seleção e na qualificação da informação, procurando compatibilizar uso e tempo para leitura. Nenhuma máquina, sozinha, poderá realizar a contento a negociação de sentido entre as instâncias de produção e recepção, a não ser partindo de um procedimento razoavelmente padronizado, ou seja, de uma interface simbólica que relacione as informações oferecidas com campos de atividades e os contextos de usos possíveis.

Na atualidade, a informação tem valor utilitário destinado ao uso presente. Sua importância desloca-se do registro para o mundo das relações. Na visão de Capurro, as mudanças podem ser representadas por três paradigmas epistemológicos, que procuramos sistematizar (Figura 1). 


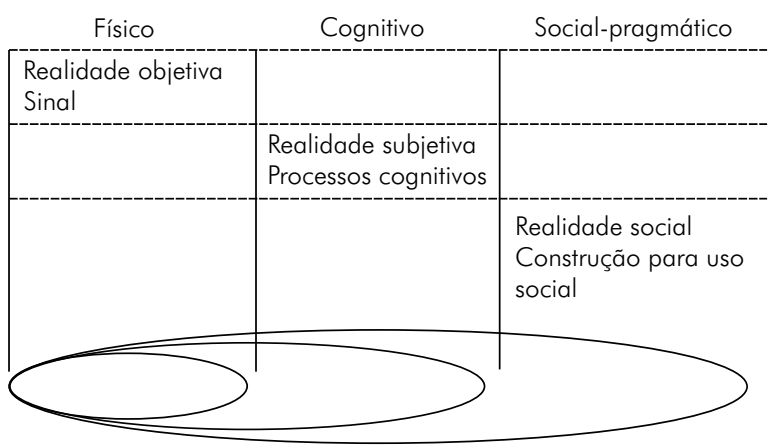

Figura 1. Representação das autoras estudo dos paradigmas epistemológicos da ciência da computação segundo Capurro.

Fonte: Mazini $(2009$, p.42).

A menção a esses paradigmas - que são verdadeiramente mais enfoques ou abordagens do que verdadeiramente paradigmas - tem como intuito salientar uma alteração no modo de compreender a informação: de algo objetivo (que transita entre uma fonte e um receptor independentemente da instância de recepção), para alguma coisa que o indivíduo subjetiva (priorização de modelos mentais, estados anômalos de conhecimento) e, em seguida, processo interpretativo que relaciona emissão e recepção envolvendo operações de contextualização e recontextualização prática do conhecimento. Esses "paradigmas" não se apresentam necessariamente em sequência, podendo ocorrer uma mobilização simultânea de aspectos de mais de um paradigma, desde que não contraditórios.

Para discutir o problema, adotou-se uma abordagem que persegue a associação do enfoque linguístico-semiótico ao terminológico, seguindo a produção de autores que advogam que a informação é uma construção de dimensões simbólicas que se expressa em linguagem, e que a informação só tem existência dentro de um contexto ou situação comunicativa concreta em que os usuários, como seres sociais, são também portadores de informações, de conhecimentos prévios e integrantes do processo de construção da informação (Kobashi; Tálamo, 2003; Lara, 2007).

Na perspectiva, são considerados os aspectos sociocognitivos que caracterizam a comunicação e a interpretação, que incluem, entre outros, referências ligadas às terminologias de áreas do saber e de atividades, ou seja, vinculadas a comunidades discursivas. Buscando soluções que possam viabilizar melhor a interação entre as instâncias de produção e de recepção da mensagem documentária, propõe-se a noção de texto não como unidade acabada, mas como lugar de interação entre atores sociais, conforme proposta da linguística textual contemporânea, noção que necessariamente considera os vínculos com os usuários (Lara; Tálamo, 2007).

Já a abordagem da informação como signo realiza a diferença existente entre esse conceito e o de sinal, tendo em vista que o processo comunicacional se desenvolve por meio de trocas simbólicas. Os sinais provocam estímulos e/ou reações, mas são entidades destituídas de recursos para a construção de significados. A corrente que associa linguística, semiótica e terminologia para abordar as relações de mediação documentária (linguística documentária), portanto, não se alinha ao paradigma físico mencionado por Capurro, já que considera que "a significação é independente da natureza do significante que a manifesta" (Lopes, 1984 , p.310). O paradigma físico também é denominado representacional, pressupondo uma relação de univocidade entre o objeto e a representação, o que não caracteriza a tendência dos autores que concebem a linguagem prioritariamente como meio de organização e comunicação (Tálamo, 1997).

\section{O TRATAMENTO DA I NFORMAÇÃO PÚ BLICA}

A informação pública pode ser definida como aquela gerada e/ou acumulada em razão das atividades do governo e convergente com os interesses ou consumo dos atores envolvidos com a esfera pública, sejam eles servidores públicos, profissionais do governo, agentes políticos ou cidadãos. $O$ direito à informação pública é historicamente construído pelas sociedades democráticas e, nesse sentido, o trabalho documentário, por proporcionar acesso e circulação, é fundamental. Segundo Jardim e Marcondes (2003, online):

A informação governamental é um dos principais componentes dos dispositivos de mediação no jogo democrático que envolve Estado e Sociedade Civil. As condições em que é produzida, estocada e disseminada dentro e fora do Estado determinam e são determinadas - direta ou indiretamente - pela diversidade de atores do cenário político-social. Isso pressupõe, no mínimo, que o Estado reconheça a informação como recurso gerencial intrínseco a todas as suas ações e objeto de políticas públicas específicas. 
Para que uma instituição pública cumpra seus objetivos e veicule informações que possam ser acessadas e compreendidas, ela deve observar a natureza das informações. No âmbito da informação pública, elas podem ser de natureza jurídica, administrativa, estatística, legislativa, jornalística, financeira, técnica, política etc. Cada uma é estruturada de modo que possa ser identificada, porque estabelece sua diferença e comunicabilidade em relação às demais.

A informação pública se organiza segundo as facetas que caracterizam as atividades governamentais e pode ser codificada sob diferentes formas - em legislação, em tabelas, em gráficos, em diferentes espécies de textos, em quadros sinóticos, em referências bibliográficas, em metadados, em resumos, em hipertexto -, dependendo do meio e das especificidades das atividades, bem como das finalidades e públicos-alvo de sua divulgação.

A escolha dos meios e dos formatos utilizados para a organização e a disseminação desse tipo de informação está diretamente relacionada à modalidade de informação em causa, com os propósitos e as disponibilidades institucionais e com as preferências do público usuário. Assim, a diversidade de formatos cobre finalidades de uso e de especialidades. Criam-se formatos para se promover "ações de informação" (Capurro, 2003; Lara; Tálamo, 2007) e para atingir as dinâmicas de interação.

Os especialistas trabalham com o estado da arte, ou seja, com a informação no sentido da geração e organização do conhecimento e, para isso, adotam determinados padrões e meios de transferência, tais como artigos, publicações, palestras e cursos, notícias, pesquisas etc. Já os documentalistas dedicam-se à organização da informação para fins de divulgação e uso. Nesse universo operam com processos, formatos e meios específicos capazes de promover a condensação necessária à promoção do acesso e à circulação do conhecimento registrado.

Na ótica documentária, a informação pública é ao mesmo tempo produto da representação de uma realidade governamental determinada e de uma possibilidade interpretativa que, embora intencional e institucional, também é passível de criatividade. Trata-se de uma informação com valor agregado qualificada para a transferência desde que se observem referências dos universos de seus públicos. Como afirmado no início deste texto, não se pode pretender que qualquer informação sirva para qualquer usuário. A formulação de linguagens documentárias para sua organização e disseminação deve observar as terminologias de domínio, ou melhor, das áreas de atividade da qual participam governo e administração pública. Isso garante o elo entre os conceitos, as representações produzidas e a instância de recepção.

Enquanto subsídio aos processos informacionais nas instituições públicas, a linguagem documentária é um instrumento que atua na produção e na recepção da informação em várias interfaces, das bibliotecas, à arquitetura de sites, passando pela elaboração e forma de apresentação de produtos eletrônicos. $\bigcirc$ recurso à terminologia - teórica e concreta - procura garantir a comunicação especializada acompanhando não só o desenvolvimento das práticas científicas, tecnológicas, administrativas que incluem a observação dos novos conceitos gerados, seus usos e traduções em diferentes níveis de linguagem. A teoria comunicativa da terminologia (Cabré, 1999), que baliza essa interface, rejeita os pressupostos clássicos da anterioridade do conceito à sua expressão em linguagem e propõe observar a manifestação do uso nos discursos.

Observa-se, porém, que as referências coletivas que dizem respeito às comunidades discursivas combinam-se aos processos de seleção da informação e modos de apropriação individuais: os textos documentários são preparados sob um ponto de vista institucional e, nesse sentido, dependem da aceitação do usuário no que se refere à sua relevância para solucionar questões práticas e/ou cognitivas particulares.

\section{CONCLUSÃO}

\section{O cenário do processamento das informações governamentais paulistas}

No regime atual, não há como separar a informação da tecnologia. Os objetivos de transparência e principalmente o esforço do governo para se aproximar do cidadão, não apenas quanto à oferta de serviços, mas quanto à criação de espaços de participação mais efetivos, fazem com que as ferramentas tecnológicas de comunicação interativas, seguindo uma tendência mundial, sejam inseridas no dia a dia da administração 
pública. Nesse contexto, desde o Decreto 53.963, de 21 de janeiro de 2009 (São Paulo, 2009), o Governo do Estado de São Paulo - em um esforço pioneiro para melhorar a eficiência, eficácia, efetividade e qualidade das políticas públicas e serviços ao cidadão e à sociedade, e a revelia de soluções tecnológicas complexas - libera a máquina estatal para o uso da internet e das ferramentas sociais da Web 2.0.

A Secretaria de Gestão Pública comanda a ação apoiada na Rede Paulista de Inovação em Governo, cuja meta é a divulgação e a capacitação dos servidores no uso das ferramentas interativas. A Resolução SGP no 15 de 25-6-2009, entre outras questões, especifica:

Artigo $1^{\circ}$ - Os Órgãos e Entidades da Administração Pública Estadual deverão promover revisão nos seus critérios e regras de acessibilidade à Internet para possibilitar o acesso de todos os seus servidores à Rede Paulista de Inovação em Governo que a Secretaria de Gestão Pública disponibiliza na Internet por meio do endereço www.igovsp.net, e às ferramentas sociais, da Web 2.0, que estão sendo utilizadas pela área de comunicação do Governo do Estado.

Parágrafo Único - Entende-se aqui por "ferramentas sociais da Web 2.0" os softwares de comunicação, colaboração, produção, armazenamento, publicação e compartilhamento de arquivos em hipermídia, disponibilizados como serviço pela Internet, tais como: serviços de rede social (comunidades virtuais); blogs; wikis; serviços de edição, hospedagem e compartilhamento de textos, planilhas, apresentações, áudio, fotos, vídeos; serviços de difusão áudio-visual por IP [...] (São Paulo, 2009).

Tal iniciativa, ainda recente, tem por finalidade promover uma mudança na cultura do setor público. A centralização de conhecimentos e de informações que antes era compreendida como um fator de estabilidade e de poder entre os funcionários passa a significar uma postura antiquada tendo em vista a cultura que se pretende instalar de compartilhamento de conhecimentos, de democratização da informação e de interatividade com a sociedade.

No que se refere às bibliotecas, nenhuma medida especial existe no decreto, levando a entender que tais serviços estão contidos na generalidade e, assim sendo, dentro de um contexto que as faz rever suas práticas de atendimento ao público. Entende-se que o processamento informacional e a tecnologia estão cada vez mais associados, sendo, portanto, imprescindível uma diversidade de formatos de divulgação da informação como meio de encaminhar sua interação e seu consumo. Sites, blogs, sistemas, redes, vídeos, publicações etc. são meios utilizados na divulgação e na transferência da cultura técnico-científica. É preciso, porém, ressaltar que os meios possuem uma linguagem própria, sendo cada um, aderente a certos tipos de mensagens, não a todas. Reconhecer essa restrição é uma forma de não confundir informação com tecnologia, ou seja, cada modalidade de informação é posta em circulação a partir de um meio que the é propício.

No caso das bibliotecas, as ferramentas em questão são úteis para a finalidade de divulgação da informação e também para a apropriação das práticas de uso da informação. Em outras palavras, a Web 2.0: "desempenha um papel significativo para que a biblioteca mantenha-se atualizada com as necessidades dos usuários, criando novos serviços interativos ou ensejando formas originais de intercâmbio" (Campos, 2007, p.9).

Contudo, no que se refere à questão de organização, especialmente ao tratamento intelectual e às formas de representação da informação, não há mudança metodológica profunda a ser feita. A informação, mesmo sob aporte tecnológico, para a ciência da informação, é resultado de procedimentos relacionados à linguagem e, nesse sentido, para ser entendida depende de estar relacionada a referenciais correlatos às áreas de especialidades. A Web 2.0 pode favorecer a aproximação da informação com determinada comunidade somente se houver sincronia discursiva entre a informação oferecida e os potenciais consumidores.

Dessa forma, do ponto de vista deste estudo, as inovações tecnológicas têm que ser aproveitadas para qualificar a oferta de informação a fim de tornar o consumo mais racional e ágil (menos dispendioso em termos de leitura). As publicações digitais, os portais, os sites, os observatórios, o blog, wiki, twitter, feed-rss são considerados elementos de um regime de informação que procura organizar e tornar imediata a recepção com foco nos interesses dos grupos por eles atendidos e para isso consideram os diferentes formatos e/ou modalidades de mensagens. Nessa perspectiva, a inclusão de ferramentas interativas no cotidiano da biblioteca inova o ambiente e influencia o seu entorno. Os fornecedores de sistemas de gestão de bibliotecas precisam inovar seus produtos, incorporando novas tecnologias e construindo sistemas que deem maior "autonomia às 
bibliotecas no acesso aos seus próprios dados" (Campos, 2007, p.9).

Portanto, a noção de biblioteca 2.0 que se vislumbra está mais relacionada à instância de recepção (aos fluxos de mensagens) do que à produção e à armazenagem de grande volume de informação para uso futuro. Também por motivos de segurança, o avanço não se ocupa do acesso às coleções nos padrões tradicionais, mas da veiculação de textos digitais originais e de mensagens que divulgam a informação em si. A folksonomia (indexação livre a partir do ponto de vista dos usuários colaboradores) pode ser um recurso precioso de coleta de termos para a elaboração e gestão

\section{REFERÊNCIAS}

CABRÉ, M.T. La terminologia: representación y comunicación. Barcelona: Institut Universitari de Lingüística Aplicada, 1999.

CAMPOS, L.F.B. Web 2.0, biblioteca 2.0 e ciência da informação: um protótipo para disseminação seletiva de informação na Web utilizando mashups e feeds RSS. In: ENCONTRO NACIONAL DE PESQUISA EM CIÊNCIA DA INFORMAÇÃO, 8., 2007, Salvador. Anais eletrônicos... Disponível em: <http://www.enancib. ppgci.ufba.br/artigos/GT2--232.pdf> . Acesso em: 27 nov. 2009.

CAPURRO, R. Epistemologia e ciência da informação. In: ENCONTRO NACIONAL DE PESQUISA EM CIÊNCIA DA INFORMAÇÃO: INFORMAÇÃO, CONHECIMENTO E TRANSDISCIPLINARIDADE, 5., 2003, Belo Horizonte. Anais eletrônicos... Disponível em: <http://www.capurro.de/enancib_p.htm>. Acesso em: 10 mar. 2008.

JARDIM, J.M.; MARCONDES, C.H. Políticas de informação governamental: a construção de governo eletrônico na administração federal do Brasil. DataGramaZero - Revista de Ciência da Informação, v.4, n.2, 2003. Disponível em: <http://www.dgz.org. br/abr03/Art 04.htm >. Acesso em: 21 abr. 2009.

KOBASHI, N.Y.; TÁLAMO, M.F.G.M. Informação: fenômeno e objeto de estudo da sociedade contemporânea. Transinformação, v. 15, Edição Especial, p.7-21, 2003. Disponível em: <http:// revistas. puc-campinas.edu.br/transinfo/viewissue. $p h p ? i d=5>$. Acesso em: 10 jan. 2010

LARA, M.L.G. Representação e linguagens documentárias: bases teórico-metodológicas. São Paulo, 1999. Tese (Doutorado em Ciências da Comunicação) - Escola de Comunicação e Artes, Universidade de São Paulo, São Paulo, 1999.

LARA, M.L.G. Informação, informatividade e linguística documentária: paralelos com as reflexões de Hjorland e Capurro. In: ENCONTRO NACIONAL DE PESQUISA EM CIÊNCIA DA INFORMAÇÃO, 8., Salvador, 2007. Anais eletrônicos... Disponível em: <http://extralibris.org/2007/12/informacao-informatividadee-linguistica-documentaria-paralelos-com-as-reflexoes-dehiorland-e-capurro/>. Acesso em: 15 fev. 2008. de linguagem documentária, mas, para este estudo, não constitui linguagem: no máximo, um rol de palavras que pode nos dar, pelo exame de sua frequência, uma noção do termo de uso preferencial. A Wiki, porque permite a construção colaborativa de textos, pode ser explorada em associação ao sistema documentário para fornecer o contexto dos termos, remeter a uma definição, ou até a um outro texto, com o intuito de explicar sua possível interpretação. Mas isso não se resume às tecnologias. As associações, os complementos ao entendimento da informação, são resultado de operações intelectuais que a tecnologia, sozinha, não pode resolver.
LARA, M.L.G.; TÁLAMO, M.F.G.M. La réception dans les procès documentaire: information et production de sens. In: COLLOQUE INTERNATIONAL DU CHAPITRE FRANÇAIS DE L'ISKO, 6., 2007, Toulouse. Actes... Toulouse: LERASS - Université Paul Sabatier; ISKO, 2007. v.6, p.79-95. Disponível em português em: <http:// www.rumores.usp.br/lara.pdf>. Acesso em: 15 jun. 2009.

LOPES, E. Fundamentos da linguística contemporânea. São Paulo: Cultrix, 1984.

LYOTARD, J. F. A condição pós-moderna. São Paulo: José Olympio, 2002.

MAZINI, E.S. A transferência e a divulgação de informações de interesse municipal. São Paulo, 2009. Dissertação (Mestrado) - Escola de Comunicação e Artes, Universidade de São Paulo, São Paulo, 2009.

SANTOS, B.S. Introdução a uma ciência pós-moderna. Rio de Janeiro: Graal, 1989.

SÃO PAULO (Estado). Decreto n ${ }^{\circ} 53.963$, de 21 de janeiro de 2009. Diário Oficial do Estado de São Paulo, 22 janeiro 2009. Caderno 1. Disponível em: <http://br.vlex.com/vid/decreto-njaneiro-59334874 >. Acesso em: 10 jan. 2010.

SÃO PAULO (Estado). Secretaria de Gestão Pública. Resolução SGP n ${ }^{\circ} 15$ de 25 de junho de 2009. Diário Oficial do Estado de São Paulo, 27 junho 2009. Seção I. Disponível em: < http:// www.igovsp.net/>. Acesso em: 4 ago. 2009.

TÁLAMO, M.F.G.M. Linguagem documentária. São Paulo: Associação Paulista de Bibliotecários, 1997. (Ensaios APB, 45).

VOGT, C. A espiral da cultura científica. 2003. Disponível em: <http://www.comciencia.br/reportagens/cultura/cultura01. shtml >. Acesso em: 14 mar. 2008.

VOGT, C. Percepção pública da ciência: uma revisão metodológica e resultados para São Paulo. In: VOGT, C. Indicadores de ciência, tecnologia e inovação em São Paulo. São Paulo: Fapesp, 2005. Disponível em: <www.fapesp.br/indicadores2004/volumel/cap12_vol1.pdf>. Acesso em: 2 jul. 2008. 
